\title{
A review of the epidemiology, post-neurosurgical closure complications and outcomes of neonates with open spina bifida
}

\author{
P C Mashiloane, MB ChB, FCPaed; R Masekela, $\mathrm{PhD}$ \\ Department of Paediatrics, Inkosi Albert Luthuli Central Hospital, Durban, KwaZulu-Natal, South Africa \\ Corresponding author: P C Mashiloane (pheladimashiloane@gmail.com)
}

\begin{abstract}
Background. Spina bifida (SB) is a neural tube defect (NTD) that has an increased risk of fatal and disabling effects if not repaired early, i.e. within the first 24 to 48 hours of life. Its diagnosis holds an increased burden for the patient and the caregiver owing to secondary complications. The effects of the disease are detrimental even with early repair, because of the long-term disabling nature of the disease. Objective. This retrospective study aimed to assess the effects of demographics, immediate post-surgical complications and impact of time to surgical intervention on the outcome of neonates with open SB (OSB) admitted to the neonatal intensive care unit (NICU) at Inkosi Albert Luthuli Central Hospital (IALCH) in KwaZulu-Natal, South Africa (SA), between January 2011 and December 2015.

Methods. A retrospective chart review was conducted at the NICU of IALCH. All neonates diagnosed with SB were identified. The study period was from 1 January 2011 to 31 December 2015. Data were collected from the IALCH electronic database. All neonates with SB admitted to the IALCH NICU were included; any patient who presented beyond the neonatal period (i.e. $>28$ days) was excluded from the study. Data collected included maternal demographics. Additionally, neonatal history was reviewed and post surgery complications evaluated. Outpatient management post discharge was reviewed.

Results. One hundred and fifty neonates were included (58\% male). The mean (standard deviation) maternal age was 26.7 (6.6) years. Only $10 \%$ had an antenatal diagnosis of OSB. Seventy-eight percent were born at term and $22 \%$ prematurely. The lumbar/sacral region was the most commonly affected. More males (14\%) had thoraco/lumbar lesions than females (7.8\%). Forty-eight percent presented before 3 days of life (early presentation). In the late-presentation group, there was an association with wound sepsis $(p=0.003)$. Twenty-five percent were repaired between days 0 and 3 of life and $75 \%$ after 3 days. Postoperative complications in patients whose open SBs were repaired beyond 3 days of life were not statistically significant compared with those with early repair; all were $p>0.05$. There was a borderline association of prolonged hospitalisation with wound sepsis $(p=0.07)$. Long-term outcomes showed that $68 \%$ had lower limb dysfunction, $18 \%$ urological complications, $14 \%$ limb deformity, and $11 \%$ hydrocephalus. A minority had psychomotor (7\%) and developmental (15\%) disorders. Ten percent required readmission secondary to shunt complications, and 7\% died.

Conclusion. SB remains a significant disease burden that affects outcome and survival of neonates in SA. Lack of good antenatal care, which includes early ultrasound and timely referral to centres, are barriers to good outcomes. Long-term follow-up is also necessary to prevent morbidity.
\end{abstract}

S Afr J Child Health 2020;14(2):75-81. https://doi.org/10.7196/SAJCH.2019.v14i2.1638

Spina bifida (SB) is one of the neural tube defects (NTDs) of primary neurulation. It results from failure of fusion in the caudal region of the neural tube and is one of the most common malformations of the human structure. NTDs are classified as open or closed. Open NTDs include meningocele (SB), myelomeningocele, encephalocele and anencephaly. Closed NTDs are confined to the spine and include encephalocele, SB occulta and cranial dermal sinus. In humans, primary neurulation extends caudally into the region of the future first to fifth sacral vertebrae and is completed by the 25 th day post conception..$^{[1]} \mathrm{SB}$ and anencephaly can result from interruption in cell adhesion or alterations in neural plate shaping or bending that prevent apposition of the neural folds. ${ }^{[2]}$

\section{Epidemiology and risk factors}

The prevalence of NTDs is 18.6/10 000 live births worldwide and 9.9/10 000 live births in South Africa (SA). ${ }^{[3,4]}$ In low-and-middleincome countries (LMICs), NTD may account for $29 \%$ of neonatal deaths secondary to congenital defects. ${ }^{[5]}$

The causes of SB are multifactorial and include chromosomal abnormalities, gene disorders and teratogenic exposure, and in some cases remain idiopathic. A family history of NTD was found in $16.9 \%$ of children with tube defects without a difference between maternal and paternal lineage. ${ }^{[6]}$ This significant rate suggests that genetics and epigenetics may play a fundamental role in the pathogenesis of NTD despite folate supplementation. ${ }^{[7]}$ Ethnic groups, parity, geographical areas and different seasons contribute to the aetiology of NTDs. ${ }^{[8]}$ Studies have noted that NTDs occur mostly in firstborn children and with lower parity, ${ }^{[0]}$ and this is because first pregnancies are usually unplanned and are associated with inadequate folate supplementation and exposure to teratogens. ${ }^{[9]}$ Other risk factors include maternal obesity and use of anti-epileptic drugs. ${ }^{[10]} \mathrm{SB}$ can be prevented by maternal peri-conception folic acid supplementation. The mechanism of the protective effect of folic acid is unknown, but it is suggested that the genes that regulate folate transport and metabolism may play a role. In SA, there are a high number of unplanned pregnancies; therefore, pre-conception folic acid supplementation is still in huge deficit, which limits prevention of SB by supplementation. ${ }^{[3]}$

The complications of SB range in severity from insignificant to paralysing and fatal defects, and hence the increased burden 
on caregivers, even post repair. The complications may include urological, renal, neurological, dermatological and musculoskeletal comorbidities. Poor quality of life in these patients is due to the numerous complications that occur concurrently. A study by Tarcan et al. ${ }^{[11]}$ observed a better prognosis for urinary symptoms in patients who had undergone surgical repair within 72 hours after birth. The higher the lesion, the more severe the outcome. ${ }^{[12]}$ Most children with open SB (OSB) have normal kidney function at birth; however, there is a small percentage who will display the effects of detrusor-sphincter dyssynergia at birth, and hence the importance of early screening for neuropathic dysfunction. Most patients complicate with chronic kidney disease secondary to bladder outlet dysfunction. ${ }^{[13]}$

Hydrocephalus is a significant complication of spina bifida. Ventricular peritoneal shunting (VPS) is the mainstay of treatment for hydrocephalus; however, it can be associated with failure and sepsis, which contribute to prolonged hospital stays. ${ }^{[14]}$ Other neurological complications are tethered cord or hydromyelia. Symptomatic tethered cord presents with muscle spasms, hyperreflexia and hypertonia and is an indication for surgery. Hydromyelia result in rapidly progressive scoliosis and weakness of the arms and legs. ${ }^{[14]}$

Musculoskeletal comorbidities depend on the site of the lesion; symptoms may vary from normal functioning to paraplegia. Apart from paralysis, patients may get muscle imbalance around the joints, with resultant hip dysplasia, talipes equinovarus, calcaneous foot, rocker-bottom feet and scoliosis..$^{[14]}$

In utero diagnosis of OSB is important for counselling and preparing parents for the birth of a child with OSB, and also affords them the options of fetal surgery or termination of pregnancy. Early diagnosis with maternal serum alpha-fetoprotein has a screening sensitivity of $\sim 80-85 \% .{ }^{[15]}$ Ultrasound can detect SB up to a rate of $96-100 \%{ }^{[16]}$ There is a gap in the antenatal diagnosis of OSB in Africa, mostly owing to lack of access to healthcare. Ultrasound prognosticates motor function by prenatally assessing the level of the lesion. ${ }^{[15,16]}$ A study in Uganda concluded that surgery for SB was essential for the survival of these children in Africa. ${ }^{[10,14]}$ A study comparing prenatal and postnatal surgery stated that prenatal surgery reduced the need for shunting and improved motor outcomes at 30 months; however, it was associated with significant maternal and fetal risks. ${ }^{[17]}$ Prenatal surgery is not yet available in SA. It is vital that closure is performed early because the exposed nerve can become infected and injured. Ideally repair should be done within $24-48$ hours of birth. ${ }^{[18]}$ One study showed a lower incidence of pre-surgical rupture of the OSB, post-surgical dehiscence and neurodevelopmental delay one year after birth if the lesion was repaired immediately after birth. ${ }^{[19]}$ Surgical repair of OSB and anaesthetic exposure may pose life-threatening complications mostly related to the associated anomalies (hydrocephalus, Chiari malformation and scoliosis). ${ }^{[20]}$ Postsurgical monitoring in a neonatal intensive care unit (NICU) or high care is required. Management of these patients requires lifelong multidisciplinary care. ${ }^{[13]}$ Caregivers and patients also require regular outpatient follow-up, rehabilitation and economic assistance. ${ }^{[7]}$ Prevention of recurrence in future pregnancies and maternal counselling are mandatory.

Patients with OSB require specialised management at tertiarylevel hospitals. In KwaZulu-Natal (KZN) province there is only one centre that provides such care for the entire province, which delays imaging and surgical repair because of limited bed capacity. Most African countries face similar challenges. ${ }^{[21]}$ A study in Nigeria revealed that late presentations, maternal illiteracy and failure to follow up are the major factors contributing to difficulty in managing these patients. ${ }^{[21]}$ The current study was therefore conducted with the aim of assessing the timing of diagnosis, immediate post surgical outcomes and long-term complications of children with OSB referred to a quaternary centre in KZN.

\section{Methodology}

A retrospective chart review was conducted at the Neonatal Intensive Care Unit (NICU) of the Inkosi Albert Luthuli Central Hospital (IALCH), KZN, SA. This government quaternary hospital has 846 beds and is the main referral centre for KZN and part of Eastern Cape provinces. The NICU has 12 ICU beds and 6 high-care beds. All neonates diagnosed with spina bifida were identified. The study period was from 1 January 2011 to 31 December 2015. Data were collected from the IALCH electronic database.

All neonates with SB admitted to the IALCH NICU were included; any patient who presented beyond the neonatal period (i.e. $>28$ days) was excluded from the study. Data collected included maternal demographics: maternal age, parity, gravidity, associated illness in pregnancy, antenatal care booking status, place of delivery, antenatal diagnosis, and family history of SB. Additionally, neonatal history was reviewed which included mode of delivery, birthweight, gestational age, risk factors, gender and age on admission to the NICU at IALCH. The clinical state of the neonate prior to surgery was documented; this entailed the level/site of the lesion, presence of wound sepsis, and other complications associated with the lesion. Post-surgery complications were evaluated and classified as immediate post-surgery and longterm complications. Outpatient management post discharge was reviewed, i.e. number of follow-up visits, readmissions, rehabilitation status, long-term complications and outcome.

Data were recorded on Excel (Microsoft Corp., USA). Exploratory data analysis used frequencies to identify outliers and miscodes. Stata version 13.1 was used to generate descriptive statistics, frequencies and percentages (StataCorp., USA). $\chi^{2}$ or Fisher's exact tests were used to compare immediate post-repair complications when repair was done early v. late. Ethical approval was obtained from the University of KZN's Biomedical Research Ethics Committee (BREC no. BE461/17) and permission to conduct the study was granted by the chief executive officer of IALCH.

Table 1. Demographics of babies with spina bifida $(N=159)$

\begin{tabular}{ll}
\hline Characteristic & $n(\%)$ \\
\hline Maternal age (years) & $63(39.6)$ \\
$15-24$ & $47(29.6)$ \\
$25-29$ & $49(30.8)$ \\
$30-45$ & $16(10.1)$ \\
Antenatal diagnosis & $143(89.9)$ \\
Yes & \\
No & $93(58.5)$ \\
Gender & $64(40.2)$ \\
Male & $2(1.2)$ \\
Female & \\
Ambiguous & $125(78.6)$ \\
Gestational age & $34(21.4)$ \\
Term & \\
Premature & $145(91.2)$ \\
ANC booking & $14(8.8)$ \\
Yes & \\
No & \\
ANC $=$ antenatal care. &
\end{tabular}




\section{Results}

One hundred and fifty-nine participants were included (58\% male) (Table 1). One hundred and forty-five (91\%) neonates were referred to the IALCH NICU from hospitals around KZN for management, while 14 (9\%) neonates were in-born. The mean maternal age was 26.7 (SD 6.6) years, with the majority (40\%) between 15 and 24 years. Only $10 \%$ had an antenatal diagnosis of OSB.

Seventy-nine percent were term deliveries and $21 \%$ were born prematurely. There was no statistical significance in the gender of the babies with OSB.

The lumbar/sacral region mostly is affected in these patients (55.6\% male and $44.4 \%$ female). However, more males (14\%) had thoraco/lumbar lesions than females (7.8\%) (Table 2). Two children with lumbar SB lesions had disorder of sexual differentiation.

More than half of the patients (52\%) presented beyond 3 days of life and $48 \%$ presented before 3 days of life. The patients who presented beyond 3 days of life had statistically significantly increased wound sepsis compared with those with early presentation $(p=0.003)$. On admission, the complications of open SB were: hydrocephalus (50\%), dysmorphic features (9\%), club foot $(40 \%)$, lower limb dysfunction (21\%), hip deformity (10\%), hip dislocation (3\%), renal complications (7\%), seizures at birth (7\%) and septic wounds (4\%) (Table 3).

Fifty-one percent (51\%) were repaired beyond 10 days of life, $43 \%$ between 4 and 9 days, and only 25\% repaired within 72 hours after birth. Of those repaired before 3 days of life, the complications were apnoea (8\%), prolonged hospitalisation (15\%), seizures (3\%), wound sepsis (18\%), meningitis/ventriculitis (5\%) and hydrocephalus requiring ventriculoperitoneal shunt (VPS) (28\%) (Table 4).

Table 2. Level of the lesion of neonates with spina bifida

\begin{tabular}{llll}
\hline Level of lesion & Male, $\boldsymbol{n}(\%)$ & Female, $\boldsymbol{n}(\%)$ & Total \\
\hline Lumbar/sacral & $49(52.7)$ & $39(60.9)$ & 88 \\
Sacral & $16(17.2)$ & $8(12.5)$ & 24 \\
Thoraco/lumbar & $13(14.0)$ & $5(7.8)$ & 18 \\
Lumbar & $14(15.1)$ & $11(17.2)$ & 27 \\
Thoracic & $1(1.1)$ & $1(1.6)$ & 2 \\
Total & 93 & 64 & 157
\end{tabular}

Table 3. Early complications of children with OSB on admission

\begin{tabular}{|c|c|c|c|c|}
\hline \multirow{2}{*}{$\begin{array}{l}\text { Immediate } \\
\text { complications }\end{array}$} & \multicolumn{2}{|c|}{ Age on admission (days) } & \multirow[b]{2}{*}{ Total $n(\%$} & \multirow[b]{2}{*}{$p$-value } \\
\hline & $0-3, n(\%)$ & $4-24, n(\%)$ & & \\
\hline $\begin{array}{l}\text { Renal } \\
\text { complications }\end{array}$ & $4(36.3)$ & $7(63.3)$ & $11(6.9)$ & 0.5 \\
\hline Wound sepsis & $0(0)$ & $6(100)$ & $6(3.8)$ & 0.003 \\
\hline Dysmorphism & $7(50.0)$ & $7(50.0)$ & $14(8.8)$ & 0.9 \\
\hline OEIS complex & $3(50.0)$ & $3(50.0)$ & $6(3.8)$ & \\
\hline Hydrocephalus & $31(38.8)$ & $49(61.2)$ & $80(50.3)$ & 0.026 \\
\hline Hip dislocation & $2(50.0)$ & $2(50.0)$ & $4(2.5)$ & 0.9 \\
\hline Club foot & $32(50.7)$ & $31(49.3)$ & $63(39.6)$ & 0.6 \\
\hline $\begin{array}{l}\text { Hip flexion } \\
\text { deformity }\end{array}$ & $6(37.5)$ & $10(62.5)$ & $16(10.1)$ & 0.4 \\
\hline $\begin{array}{l}\text { LL dysfunction } \\
\text { pre-repair }\end{array}$ & $58(46.4)$ & $67(53.6)$ & $125(78.6)$ & 0.5 \\
\hline Seizure at birth & $5(45.4)$ & $6(54.6)$ & $11(6.9)$ & 0.9 \\
\hline
\end{tabular}

The postoperative complications in patients repaired beyond 3 days of life included: apnoea (5\%), prolonged hospitalisation (22\%), seizures (8\%), wound sepsis (34\%), meningitis (13\%), hydrocephalus requiring VPS (28\%) but none was statistically significant compared with those with early repair (all $p>0.05$ ). There was a borderline association between prolonged hospitalisations with wound sepsis $(p=0.07)$.

Regarding follow-up, $38 \%$ had only 2 visits, $36 \%$ had $3-6$ visits, and $26 \%$ had $>10$ visits. Long-term complications identified were: $68 \%$ lower limb paralysis/dysfunction, $18 \%$ urological complications, $14 \%$ limb deformity, and $11 \%$ hydrocephalus, of which $3 \%$ was associated with raised intracranial pressure while $5 \%$ had arrested hydrocephalus. VPS sepsis and blockage were observed in $4 \%$ and $6 \%$, respectively. Fourteen percent had developmental delay, $7 \%$ psychomotor disorder, $3 \%$ seizures, $3 \%$ septic wounds, $2 \%$ upper airway obstruction (UAO) and $10 \%$ required re-admission. Three percent were palliated owing to associated complex complications and dysmorphism not compatible with life. The mortality for the cohort was $7 \%$.

\section{Discussion}

Spina bifida is the most common congenital disorder involving the nervous system; the demographic risk factors have been extensively researched. ${ }^{[6-10]}$ In the current study, the mean maternal age was 26.7 years, of whom $40 \%$ were between 15 and 24 years. Unlike previous studies in LMIC settings, mortality from OSB was $7 \%$ overall, far lower than the reported $29 \%$

Table 4. Immediate post-spina bifida repair complications v. days of life of repair

\begin{tabular}{|c|c|c|c|c|}
\hline \multirow[b]{2}{*}{$\begin{array}{l}\text { Immediate } \\
\text { complications }\end{array}$} & \multicolumn{2}{|c|}{ Age at repair } & \multirow[b]{2}{*}{$\begin{array}{l}\text { Total } \\
n(\%)\end{array}$} & \multirow[b]{2}{*}{$p$-value } \\
\hline & $\begin{array}{l}0 \text { - } 3 \text { days, } \\
n(\%)\end{array}$ & $\begin{array}{l}>3 \text { days, } \\
n(\%)\end{array}$ & & \\
\hline \multicolumn{5}{|l|}{$\mathrm{UAO}$} \\
\hline Yes & $1(2.6)$ & $6(5.0)$ & 7 & 0.9 \\
\hline No & $38(97.4)$ & $114(95.0)$ & 152 & \\
\hline \multicolumn{5}{|l|}{ Palliation } \\
\hline Yes & $3(7.7)$ & $2(1.7)$ & 5 & 0.095 \\
\hline No & $36(92.3)$ & $118(98.3)$ & 154 & \\
\hline \multicolumn{5}{|l|}{ Wound sepsis } \\
\hline Yes & $7(17.9)$ & $41(34.2)$ & 48 & 0.07 \\
\hline No & $32(82.1)$ & $79(65.8)$ & 111 & \\
\hline \multicolumn{5}{|c|}{ Meningitis/ventriculitis } \\
\hline Yes & $2(5.0)$ & $16(13.3)$ & 18 & 0.2 \\
\hline No & $37(95.0)$ & $104(86.7)$ & 141 & \\
\hline \multicolumn{5}{|c|}{ HCP requiring VPS } \\
\hline Yes & $11(28.2)$ & $34(27.5)$ & 45 & 0.9 \\
\hline No & $28(71.8)$ & $87(72.5)$ & 115 & \\
\hline \multicolumn{5}{|l|}{ Apnoea } \\
\hline Yes & $3(7.7)$ & $6(5.0)$ & 9 & 0.7 \\
\hline No & $36(92.3)$ & $114(95.0)$ & 150 & \\
\hline \multicolumn{5}{|l|}{ Seizure } \\
\hline Yes & $1(2.6)$ & $9(7.5)$ & 10 & 0.5 \\
\hline No & $38(97.4)$ & $111(92.5)$ & 149 & \\
\hline \multicolumn{5}{|c|}{ Prolonged hospitalisation } \\
\hline Yes & $6(15.4)$ & $26(21.7)$ & 32 & 0.5 \\
\hline No & $33(84.6)$ & $94(78.3)$ & 127 & \\
\hline
\end{tabular}


in other LMIC settings. ${ }^{[6]}$ There was no familial risk factor identified in this cohort in comparison with reported rates of $16.9 \% .^{[6]}$ The retrospective nature of the present study may to some extent explain this discrepancy. There was also no gender predilection demonstrated, albeit a slight male preponderance found $;^{[6]}$ Komolafe et al..$^{[21]}$ also made this observation. Thoraco/ lumbar lesions were also more commonly found in $14 \%$ of males as compared with $7.8 \%$ of females; this conflicted with previous studies, which documented that males commonly present with lower vertebral lesions. ${ }^{[6]}$ The lumbar/sacral regions were the most commonly affected with OSB in the current study. Ultrasound as the main tool for antenatal diagnosis and prognostication was rarely utilised, with only $10 \%$ of patients being diagnosed with this modality. Previous studies demonstrated better outcomes associated with antenatal diagnosis of SB. ${ }^{[14,15]}$

Surgical intervention for OSB is essential for the survival of affected children in Africa. ${ }^{[8,13]}$ On comparison of complications encountered by the patients whose OSB was repaired within 3 days of life (early) and beyond 3 days of life (late), the majority (over 75\%) were repaired late. Late diagnosis and repair have been found to negatively affect the management and outcomes of these patients. ${ }^{[17,21]}$ Critical areas observed in the current study that were associated with delay, were limited bed capacity at the quaternary hospital and late imaging because of waiting times.

$\mathrm{SB}$ is associated with multiple comorbidities at birth. These include hydrocephalus, renal and neurological complications, and orthopaedic effects. ${ }^{[11]}$ In the current study, half the neonates were born with hydrocephalus. Usually, gross hydrocephalus does not occur until after the OSB is repaired, and this occurred in $28 \%$ who subsequently required VPS. ${ }^{[14]}$ Of those with VPS, $13 \%$ developed meningitis as a postoperative complication.

A third of neonates (34\%) developed immediate postoperative complications with wound sepsis, and $22 \%$ required prolonged hospitalisation post OSB repair. There was a borderline association of prolonged hospitalisation with wound sepsis $(p=0.07)$, which was secondary to wound dehiscence. Pinto et al. ${ }^{[17,19]}$ showed a lower incidence of pre-surgical rupture of the SB, post surgical dehiscence and a lower incidence of neurodevelopmental delay one year after birth, if repair of the lesion was carried out immediately after birth. However, Komolafe et al. ${ }^{[21]}$ did not observe an association between delayed repair and wound sepsis $(p=0.56)$.

Danzer et al. ${ }^{[22]}$ assessed long-term neurofunctional outcomes, executive function and behavioural adaptive skills following fetal SB surgery and concluded that fetal SB surgery improves neurofunctional outcome; however, bowel and bladder control is an ongoing challenge. Although fetal SB surgery has not yet been established at IALCH, the present study observed that 125 (78\%) patients had limb dysfunction at birth prior to neurosurgical repair and, on long-term follow-up, 89 (56\%) patients still had limb dysfunction. A randomised controlled trial comparing prenatal and postnatal surgery, concluded that prenatal surgery for SB reduced the need for shunting and improved motor outcomes at 30 months. ${ }^{[17]}$ SB can result in bladder dysfunction in addition to lower-limb neurological abnormalities. ${ }^{[23]}$ It is shown in the present study that at birth there were 83 patients with overall limb deformity (club foot, hip dislocation or flexion deformity); when reviewed post surgery, limb deformities persisted in only 23 patients.

Of the $30 \%$ of subjects with sacral lesions, $18 \%$ had neurogenic bladder and faecal incontinence. These bladder issues were only identified after toilet training was achieved, and hence there was late referral to urologists. Johnston et al. ${ }^{[2]}$ also recognised such bladder and bowel complications in their study.

On follow-up, $4 \%$ had septic shunts and $6 \%$ had blocked shunts. Other studies have noted shunt failure to be a major long-term complication long-term. ${ }^{[23]}$ This poses difficulties in the management of severe hydrocephalus because VPS is the mainstay of treatment. The $7 \%$ mortality in this study was related to shunt complications, but this is lower than the reported rate in other LMICs. ${ }^{[6]}$

\section{Study limitations and strengths}

The retrospective nature of the study was limited in terms of the data that could not be captured, including family history of SB and number and first antenatal clinic attendance as well as documentation of folic supplementation. Long-term complications may also be biased towards those children who had more severe complications, and therefore these were the ones who attended follow-up, while those who had to travel long distances may have been unable to return, despite the presence of complications.

The sample size was reasonably large, and it included participants from a large geographic region of KZN and Eastern Cape provinces. IALCH is the only centre which provides neurosurgical services for the state in KZN; consequently all possible children in the province were captured. The immediate complications and factors which caused delay in closure were all documented.

\section{Conclusion and recommendations}

In the current study of OSB, lower maternal age and delay in diagnosis and closure of OSB were found, which were related to lack of access to early neonatal ultrasound and lack of beds at the referral centre for early repair of lesions. The delay in surgical interventions resulted in higher rates of wound sepsis and therefore prolonged hospitalisation on admission. Despite this issue, mortality rates were lower than those reported in other LMICs.

Primary health facilities should encourage women of childbearing age to take supplements, especially folic acid during preconception and pregnancy. Education of the general public on the importance and need for folic acid supplementation should be pursued. There is a need for a co-ordinated and comprehensive approach at multiple levels of care from primary, secondary and quaternary levels on the acute management, early referral and intervention for children with OSB to prevent wound sepsis in particular, as well as secondary complications. This model requires health system changes (e.g. clear care pathways), physical and human resources, and training of health professionals. Finally, the caregivers of children with OSB require education and social support to facilitate follow-up care and rehabilitation of these children.

Declaration. This manuscript was submitted in partial fulfilment of the requirements for a MMed( Paeds) degree.

Acknowledgements. We appreciate the assistance of the Department of Neurosurgery and the NICU at IALCH in accessing patients' records.

Author contributions. PCM: conceptualisation of topic, data collection and analysis, manuscript draft and write-up. RM: revision of topic, data analysis, interpretation and overall supervision.

Funding. None.

Conflict of interest. None. 
1. Copp AJ, Green NDE, Murdoch JN. The genetic basis of mammalian neurulation. Nat Rev Genet 2003;4(10):784-793. https://doi.org/10.1038/nrg1181

2. Van Allen MI, Kalousek DK, Chernoff GF, et al. Evidence for multi-site closure of the neural tube in humans. AM J Med Genet 1993;47(5):723-743. https://doi. org/10.1002/ajmg.1320470528

3. Teckie G, Krause A, Kromberg JG. Neural tube defects in Gauteng, South Africa: Recurrence risk and associated factors. S Afr Med J 2013;103(12):973-977. https://doi.org/10.7196/samj.7119

4. Blencowe H, Kancherla V, Moorthie S, Darlison MW, Modell B. Estimates of global and regional prevalence of neural tube defects for 2015: A systematic analysis. Ann NY Acad Sci 2018;414(1):31-46. https://doi.org/10.1111/ nyas. 13548

5. Mohammed ZS, Omar BA, Meeralebbae MS, et al. Epidemiology of neural tube defects. Saudi Med J 2014;35(1):S29-S35. https://doi.org/10.15537/smj.11087

6. Dupépé EB, Patel DM, Rocque BG, et al. Surveillance survey of family history in children with neural tube defects. J Neurosurg Pediatr 2017;19(6):690-695. https://doi.org/10.3171\%2F2016.12.PEDS1668

7. Mitchell LE. Epidemiology of neural tube defects. Am J Med Genetics 2005;135(1):88-94. https://doi.org/10.1002/ajmg.c.30057

8. Fieggen K, Stewart C. Aetiology and antenatal diagnosis of spina bifida. S Afr Med J 2014;104(3):218. http://doi.org/10.7196\%2FSAMJ.8039

9. Benjamin C, Vita S, Mugamba J, et al. Encephalocoele in Uganda: Ethnic distinction in lesion location, endoscopic management of hydrocephalus and survival in 110 consecutive children. J Neurosurg Paediatr 2011;7(1):88-93.

10. Werler MM, Ahrens KA, Bosco JL, et al. Use of antiepileptic medications in pregnancy in relation to risks of birth defects. Ann Epidemiol 2011;21(11): 842850. https://doi.org/10.1016/j.annepidem.2011.08.002

11. Tarcan T, Onol FF, Ilkel Y, et al. The timing of primary neurosurgical repair significantly affects neurogenic bladder prognosis in children with myelomeningocele. J Urol 2006;176(3):1161-1165. https://doi.org/10.1016/j. juro.2006.04.042

12. Ong LC, Lim NY, Sofiah A. Malaysian children with spina bifida: Relationship between functional outcome and level of lesion. Singapore Med J 2002;43(1):012-017.

13. Filler G, Mireille G, Casier S, et al. Prevention of chronic kidney disease in spina bifida. Int Urol Nephrol J 2012;44(3):817-827. https://doi.org/10.1007/s11255010-9894-5

14. Phillips LA, Burton JM, Evans SH. Spina bifida management. Curr Probl Pediatr Adolesc Health Care 2017;47(7):173-177. https://doi.org/10.1016/j. cppeds.2017.06.007
15. Wald NJ, Cuckle $\mathrm{H}$, Brock JH, et al. Maternal serum-alpha-fetoprotein measurement in antenatal screening for anencephaly and spina bifida in early pregnancy. Report of UK collaborative study on alpha-fetoprotein in relation to neural-tube defects. Lancet 1977;1(8026):1323-1332.

16. Dashe JS, Twickler DM, Santos-Ramos R, et al. Alpha-fetoprotein detection of neural tube defects and the impact of standard ultrasound. Am J Obstet Gynecol 2006;195(6):1623-1628. https://doi.org/10.1016/j.ajog.2006.03.097

17. Adzick NS, Thom EA, Spong CY, et al. A randomized trial of prenatal versus postnatal repair of myelomeningocele. N Engl J Med 2011;364(11):993-1004. https://doi.org/10.1056/nejmoa1014379

18. Spiliopoulos M, Iqbal S, Reddy U, et al. Neonatal outcomes by attempted mode of delivery and obstetric intervention for pregnancies affected by spina bifida. Obstet Gynecol 2017;129(5):188S. https://doi/10.1097/01. AOG.0000514163.09127.5e

19. Pinto FC, Matushita H, Furlan AL, et al. Surgical treatment of myelomeningocele carried out at 'time zero' immediately after birth. Pediatr Neurosurg 2009;45(2):114-118. https://doi.org/10.1159/000209285

20. Singh D, Rath GP, Dash HH, et al. Concerns and perioperative complications in repair of myelomeningocele, a retrospective review of 135 cases. J Neurosurg Anesthesiol 2010;22(1):11-15. https://doi.org/10.1097/ana.0b013e3181bb44a9

21. Komolafe EO, Onyia CU, Ogunbameru IO. et al. The pattern, peculiarities, and management challenges of spina bifida in a teaching hospital in Southwest Nigeria. Child Nerv Syst 2018;34(2):311-319. https://doi.org/10.1007/s00381017-3614-8

22. Danzer E, Thomas NH, Thomas A, et al. Long-term neuro-functional outcome, executive functioning and behavioural adaptive skills following fetal myelomeningocele surgery. Am J Obstet Gynecol 2016;214(2):269.e1-269.e8. https://doi.org/10.1016/j.ajog.2015.09.094

23. Iskandar BJ, Tubbs S, Mapstone TB, et al. Death in shunted hydrocephalic children in the 1990s. Pediatr Neurosurg 1998;28(4):173-176. https://doi. org/10.1159/000028644

24. Johnston LB, Borzyskowski M. Bladder dysfunction and neurological disability at presentation in closed spina bifida. Arch Dis Child 1998;79(1):33-38. https:// doi.org/10.1136/adc.79.1.33

Accepted 17 October 2019 